\title{
Demand- and supply-side factors affecting utilisation and provision of maternal health services under the free maternal health care policy in one municipality in Northern Ghana
}

Philip Ayizem Dalinjong ( $\sim$ padalinjong@yahoo.com )

Navrongo Health Research Centre https://orcid.org/0000-0002-7982-9975

Alex Y Wang

University of Technology Sydney

Caroline SE Homer

Burnet Institute

\section{Research}

Keywords: Free maternal health policy, maternal health service, demand-side, supply-side, provision, utilisation, Ghana

Posted Date: October 1st, 2021

DOl: https://doi.org/10.21203/rs.3.rs-934211/v1

License: (c) (1) This work is licensed under a Creative Commons Attribution 4.0 International License.

Read Full License 
1 Title page

2

3

Demand- and supply-side factors affecting utilisation and provision of maternal health

4 services under the free maternal health care policy in one municipality in Northern

\section{Ghana}

6

7

$8 \quad$ Philip Ayizem Dalinjong ${ }^{1 *}$, Alex Y Wang ${ }^{2}$, Caroline SE Homer $^{3}$

9

1.Navrongo Health Research Centre, Ghana Health Service, Upper East Region, Ghana

2.Faculty of Health, University of Technology Sydney, New South Wales, Australia

3.Burnet Institute of Medical Research Institute, Melbourne, Victoria, Australia

13

*Correspondence author: padalinjong@yahoo.com

15 


\section{Abstract}

\section{Background}

4 A free maternal health care policy was introduced in Ghana in 2008 to cater for the health needs

5 of pregnant women for the reduction of maternal deaths. Experiences from other regions and

6 countries show that demand- and supply-side factors often affect the success of such policies

7 although this is unknown in this context. The study aimed to assess demand- and supply-side

8 factors affecting the utilisation and provision of services during pregnancy under the policy.

$9 \quad$ Methods

10 A convergent parallel mixed methods study was undertaken, collecting quantitative and qualitative data. The study was carried out in the Kassena-Nankana East Municipality in Ghana. Questionnaire were used to collect data from women $(n=406)$ who utilised services during pregnancy. Focus group discussions with women $(n=10)$ and in-depth interviews with midwives and nurses $(n=25)$ were also conducted. Quantitative data were analysed and presented using descriptive statistics. Qualitative data were audio-recorded, transcribed and coded using themes and sub-themes.

\section{Results}

Both demand- and supply-side factors impacted the use and provision of services. Distance and time to facilities challenged the use of services. Supply-side factors such as laboratory services, equipment, drugs and supplies were not adequately available. Antenatal, childbirth and postnatal services were carried out together in the same rooms at the community-based health planning and services (CHPS) compounds. Emergency transport was also unavailable for referral of emergencies.

\section{Conclusion}


1 Demand- and supply-side factors were reported to impede the use and provision of services.

2 Government and stakeholders should prioritise building as well as expanding the infrastructure

3 of CHPS compounds. Emergency transport for women should also be provided. These together

4 may contribute to improving the use and provision of services, leading to a reduction in 5 maternal deaths and achievement of universal health coverage.

6

7 Keywords: Free maternal health policy, maternal health service, demand-side, supply-side, 8 provision, utilisation, Ghana 


\section{Background}

3 The enactment of the National Health Insurance Act 650 (2003) brought forth the National

4 Health Insurance Scheme (NHIS) in Ghana, which became fully operational in $2005(1,2)$. The

5 NHIS aims to promote the utilisation of health services for all Ghanaians. It is a key strategy

6 for the achievement of universal health coverage. The NHIS has a defined benefit package

7 which covers about $95 \%$ of disease conditions in Ghana $(1,2)$. Exemptions are granted under

8 the NHIS for vulnerable groups like pregnant women, which comes under the free maternal

9 health policy. Given that insured women were more likely to use antenatal, childbirth and postnatal services (3-6), leading to reduced maternal deaths (7-9).

Over the years, Ghana had experienced a consistent reduction in her maternal mortality ratio, from 484 per 100,000 live births in 2000, to 371 in 2005, 339 in 2010 and 320 in 2015 (10).

Nonetheless, the rate of reduction was considered to be inadequate (10). As at 2017, Ghana recorded a maternal mortality ratio of 308 per 100, 000 live births (10). To accelerate the reduction of maternal deaths, the government of Ghana adopted the free maternal health care policy in July 2008, under the NHIS. The policy is meant to increase the use of health services, with the ultimate goal of reducing maternal deaths as well as providing universal health coverage for women and babies.

Under the policy, pregnant women are given free registration with the NHIS, with no payment of premium or processing charges. Health services, including drugs are provided free of charge during the periods of pregnancy, childbirth and postpartum (11). Following the implementation of the policy, a cumulative total of over 2 million women had benefitted at the end of 2013 , which is considered a significant achievement for the NHIS and the country (12). A recent 
1 study in the Northern and Central regions of Ghana revealed that, the policy had promoted the

2 use of health services by women (13).

$4 \quad$ The success of health policies in terms of implementation or coverage are often affected by

5 demand- and supply-side factors. Demand-side factors are the individual, household or

6 community level factors which either promote or impede the use of health services. These

7 generally include distance and time taken to reach health facilities, cost of transport to health

8 facilities, means of transport available, education, information on health services or health

9 providers, community and cultural preferences and household expectations $(14,15)$. Supply-

10 side factors refer to the characteristics of the health system which are beyond the control of consumers of health services, but have an impact on the provision of health services $(14,16$, 17). These health system factors include opening and closing hours of health facilities, cost of health services, availability of health providers, drugs and supplies, equipment and infrastructure. However, according to Jacobs et al, demand- and supply-side factors are often interrelated (15).

17 Collectively or individually, demand- and supply-side factors affect the use and provision of maternal health services. For instance, a study in the Lao People's Democratic Republic reported that cost of transport to health facilities, cultural practices and language were the main demand-side factors which adversely affected the use of services under the maternal, neonatal and child health program (18). Supply-side factors identified in the study included the lack of health providers, poor salaries, weak technical support and supervision and limited equipment which affected the provision of services (18). In an urban hospital in Southern Ghana, supplyside factors such as lack of drugs and supplies, limited incentives for health providers, high workloads, and inadequate staff impeded the provision of focused antenatal care to pregnant 
1 women (19). Another study in the Upper West region of Ghana revealed the lack and cost of

2 transport (demand-side factor) challenging the use of maternal health services (20).

4 Few studies have examined both demand- and supply-side factors affecting the use and 5 provision of maternal health services in a rural poor setting, such as the Kassena-Nankana East

6 Municipality in Ghana $(15,21,22)$. Aside that, a recent study demonstrated that women in the

7 Kassena-Nankana area had a continuum of care completion rate of $14.0 \%$; that is, women who made 4 or more antenatal visits, used a health facility for childbirth and were available for

9 postnatal services within 48 hours, and at two weeks as well as six weeks (23). Given these, there is the need to carry out investigations in that direction. Thus the aim of this paper was to assess demand- and supply-side factors affecting the utilisation and provision of free maternal health services during pregnancy in the Kassena-Nankana East municipality. The views and perceptions of women who utilised health services during pregnancy as well as frontline health providers (midwives and nurses) were studied.

\section{Methods}

\section{Study design}

A convergent parallel mixed methods study was adopted, utilising quantitative and qualitative data collection techniques (24). A mixed methods approach was adopted to ensure comprehensiveness and confidence in the study findings (25-27). The use of the convergent parallel mixed methods design allowed for data collection and analysis for the quantitative and qualitative studies to be carried out in a parallel form; while the findings are integrated to assure a comprehensive analysis of the research question (24); that is, factors affecting the use and provision of maternal health services under the free maternal health policy. The study was cross-sectional and data collection was carried out from March-August, 2016. A structured 
1 questionnaire was administered to women who had utilised maternal health services during

2 pregnancy. The qualitative aspect involved focus group discussions (FGDs) with similar

\section{$6 \quad$ Study area}

7 The study was set in the Kassena-Nankana East Municipality which is located in the Upper

8 East region of Northern Ghana. The Kassena-Nankana East Municipality was selected as the

9 study area due to the fact that it was well mapped out by the Navrongo Health Research

Centre for research and hence convenient for the study team. The study was time bound and financially constrained to select other districts or regions for investigation. The population of the municipality was estimated to be 108,000 ; with males and females constituting $48.8 \%$ and $51.2 \%$ respectively $(28)$

The Community-based Health Planning Services, also known as CHPS compounds, dominated in the provision of basic health services in the municipality (18 in number), followed by clinics (3), health centres (2) and one hospital (29). The CHPS compounds are equipped with a community health officer (a nurse) to provide basic health services to members of the communities in which they are located. Lately, midwives have been allocated to some CHPS compounds to provide antenatal, childbirth and postnatal services. CHPS compounds in Ghana are the key to the achievement of universal health coverage. Each CHPS compound was meant to serve a population of around 500 people, but currently they are allocated based on electoral areas, which are 6,135 in number $(30,31)$.

\section{Sampling}


1 The formula for a proportion in a single cross-sectional survey was used for the estimation of

2 the sample size for the quantitative study (32). A total of 406 women were recruited

3 representing women who utilised health services during pregnancy.

4

5 The qualitative component of the study comprised of 10 FGDs and 25 IDIs. The FGDs were carried out with women who used health facilities during pregnancy. The IDIs were purposefully carried out among frontline maternal health providers (midwives and nurses) who provided services in NHIS accredited health facilities (same health facilities where the survey took place).

\section{Study tools}

The tools for the survey, FGDs and IDIs were developed based on demand- and supply- side factors that are known to affect the utilisation and provision of health services $(15-17,33-$ 36). The questions on demand-side factors focused on the perceptions of distance, time and mode of transport used to reach health facilities, as well as waiting times from the perspective of women. The supply-side assessed the availability of health facilities (opening and closing hours), basic services including laboratory testing, health workforce, infrastructure, equipment and drugs and supplies for the provision of maternal health services. The survey and FGDs with the women mostly addressed demand-side factors, while the IDIs with midwives and nurses addressed supply-side factors. However, some demand-side issues emerged from the IDIs with the midwives and nurses. The survey and FGDs were piloted with women and the IDIs with midwives and nurses before the commencement of the data collection. Alterations were made when identified as necessary which were very minimal.

\section{Quantitative data collection}


1 The quantitative data were collected electronically using SurveyCTO. For a health facility to

2 be included in the study, it must have at least a midwife to offer antenatal, childbirth and

3 postnatal services, since the study sought to capture data pertaining to all these aspects of

4 maternal health services. Thus, the study recruited women from the main hospital, two (2)

5 health centres, and eleven (11) CHPS compounds across the municipality. Two trained

6 research assistants were responsible for visiting the health facilities on a daily basis for the

7 identification of women who gave birth and were discharged to go home. After consent, the women were surveyed. All women who were invited agreed to participate in the study. The inclusion criteria were that women should have utilised maternal health services during pregnancy; to be able to report their experiences. Women should have also given birth between $1^{\text {st }}$ January-31 $1^{\text {st }}$ August, 2016; to assist minimise recall bias. The recruitment process was supervised by the main investigator on a daily basis. The process of administering the questionnaire to a participant lasted about 30-45 minutes.

\section{Qualitative data collection}

Semi-structured interview guides were developed in English for both the FGDs and the IDIs. The guide for the FGDs in particular, was translated by language experts into the two dialects (Kasem and Nankam) spoken in the study area. Hence the discussions were done in the two dialects. The guide for the IDIs was not translated because all the midwives and nurses spoke and understood English. All the FGDs and IDIs were audio-recorded with the permission of the women, midwives and nurses. Field notes were also taken alongside the recordings.

The women were invited to participate in the FGDs with the assistance of midwives and nurses. The visit of the women to participate in the FGDs were planned to coincide with their routine health facility visits. The FGDs were conducted in private rooms in the health 
1 facilities, without the presence of health providers. This allowed participants to freely express

2 themselves on the issues discussed. Approximately 5-12 members formed a group for each

3 of the FGDs. All group members were encouraged by the investigator to partake in the

4 discussions.

5

6 For the IDIs, the main investigator contacted and invited the midwives and nurses to

7 participate. The IDIs were held in rooms at the health facilities. The interviews were

8 conducted one on one basis, exclusive to other people. This was to promote privacy. All

9 FGDs and IDIs lasted between 45-120 minutes. The main investigator was responsible for

10 the conduct of the FGDs and IDIs.

After the FGDs and IDIs, a summary of the issues that emerged from the discussions and interviews were made and presented back to the participants for their validation. New issues emerging from the discussions and interviews which were considered to be important were added to the questions on the interview guides for the next round of discussions and interviews. Data saturation was reached in the FGDs and IDIs when discussants and interviewees had nothing to say or talk about upon prompts and probes from the main investigator (37).

\section{Data analysis and management}

The data were cleaned and analysed using STATA 14. Descriptive statistics were used to present the findings. The qualitative data were manually analysed. The audio data were transcribed verbatim into English. The transcriptions and field notes were examined to identify patterns in the data. To assure validity and accuracy of the data, a random sample of $5 \%$ of the recordings were selected, listened to and compared with the transcriptions, of which differences were corrected before coding. However, a negligible difference was 
1 observed between the recordings and the transcripts. A follow up reading of the transcripts

2 and interview notes were carried out, noting important issues brought out by the participants.

3 A coding system was then adopted using themes and sub-themes (where necessary) and this

$4 \quad$ was presented in text tables. The coding system based on the themes and sub-themes formed

5 the basis for the presentation of the findings, including essential quotes emanating from the

6 participants.

7

8 Results

9 Demand-side

10 Socio-demographic characteristics of participants

11 A total of 406 women completed the survey. The mean age of the women was 27 years. Thirty one percent were 25-29 years of age. Majority of participants were married (95.1\%), and with only basic education (55.7\%). Over one third of the women were engaged in farming (38.2\%) (Table 1).

Table 1: Socio-demographic characteristics of participants

Time taken to reach nearest health facility irrespective of mode of transport

Most of the women perceived time taken to reach nearest health facility as a challenge. Altogether, 58\% (236/406) of the women reported that they had travelled between 30 minutes and one hour or one to two hours to reach the nearest health facility, without regard to mode of transport (Figure 1). Around 5\% (20/406) of the women perceived that they had travelled for more than two hours. 
1 Figure 1: Perceived time taken to reach nearest health facility irrespective of mode of

2 transport

Time taken to travel

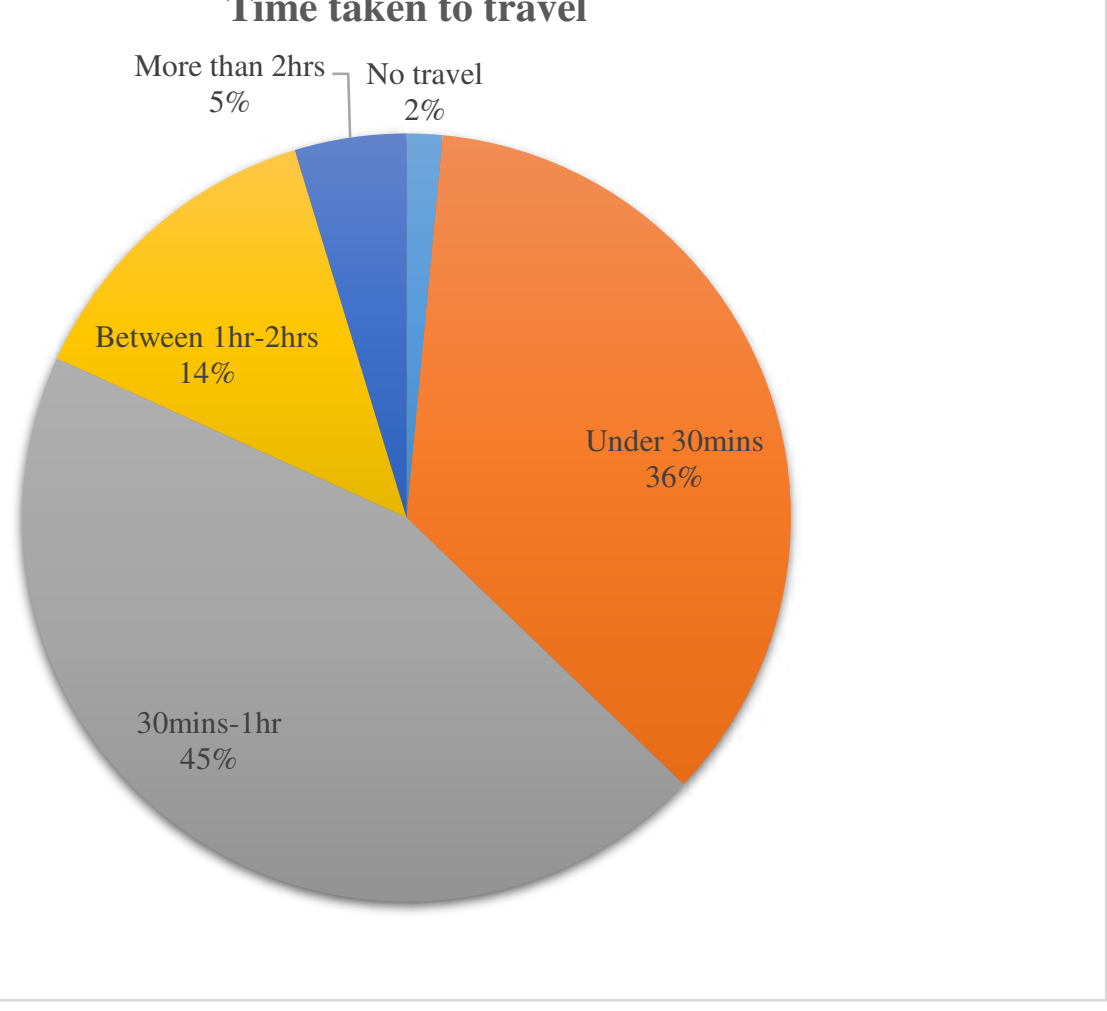

3

4

5 Perceived distance and mode of transport to nearest health facility during pregnancy

6 Over two-thirds of the women $(69.2 \% ; 281 / 406)$ reported walking to nearest health facility for

7 maternal health services during pregnancy, with variation by perceived distance (Table 2).

8 More than a quarter of the women $(26.1 \%$ (106/406) perceived distance to be either far or very

9 far, using various means of transport to get to nearest health facility. Thus, distance to health

10 facilities was also a barrier to the use of health services in the study area. 
2 Table 2: Perceived distance and mode of transport to nearest health facility

4 But findings from the FGDs and IDIs run counter to the survey. The women indicated that 5 distance to nearest health facility was not a considerable barrier for some of them. A woman 6 said:

7 '....... it is not far too and that helps us, if you have work to do you can come and go back to do your work' (FGD, woman).

A midwife also reported: like undergoing a caesarean section due to a complication. A midwife said: cases. It'll take a long time to reach the hospital' (IDI, midwife). 
2 Waiting times at nearest health facility during pregnancy

3 Over half of the participants perceived waiting times to be either short or normal (Figure 2).

4 Approximately 6\% (24/406) of the women perceived that their waiting times were 'very long'.

5

$6 \quad$ Figure 2: Perception of waiting times at nearest health facility during pregnancy

7

8

9

10

11

12

\section{Waiting times at nearest health facility}

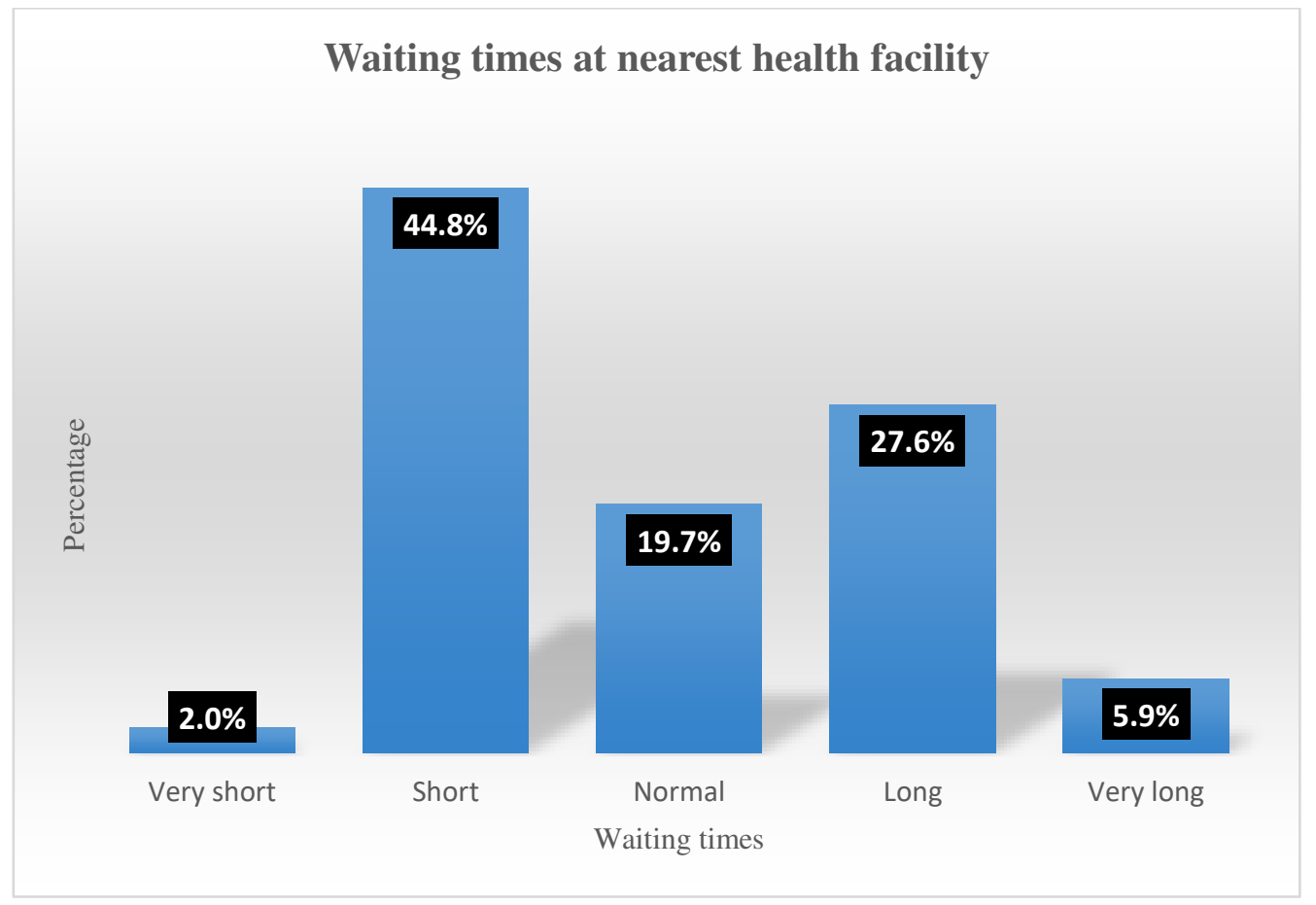

Supply-side

1 Opening and closing hours of health facilities

2 In the IDIs, it was reported that the main (and only) hospital in the municipality had in place a

3 shift system for health providers; which meant the availability of staff to provide health services 4 to clients at all times. The hospital is the only referral point for lower level health facilities and hence it had no opening and closing hours. Likewise, those lower level health facilities with residential accommodation were able to provide health services to women, even at night. A nurse said: 
'For those of us who even stay here, we don't even have an opening and closing time because we operate 24 hours a day. At any time that a sick person comes, we are always there to take care of that person. So, we are always there 24 hours' (IDI, nurse).

5

6 Those health facilities without residential accommodation for staff had more restricted opening hours (8:00 am to 5:00 pm). Many of the health facilities though could only close when the last client departed. For example, a midwife said: 'By 8:00 we're here, but closing time; it's the clients that determine our closing time. So sometimes we end up running a 24-hour service. When you're having a woman in

From the perspective of health providers, health services were readily available at any time.

This was contrary to views of some of the women who felt they could visit health facilities in the night with serious problems, but health providers (midwives and nurses) would not be available to attend to them. A woman said: 'They can go into their rooms or go home and people will come and will not meet any nurse..........I remember a woman was brought here and they knocked but no one came out ........' (FGD, woman). 
1 The FGDs also showed that in emergent situations, women and their relatives visit other

2 facilities (regardless of the distance) when health providers were not available in the nearest

3 health facility to attend to them. A woman reported:

4

'In the night, my husband had to pick me on a motor [motorbike] to Navrongo [location of district hospital] when I started experiencing pains in my stomach' (FGD, woman).

\section{Availability of basic health services and laboratory testing}

Midwives and nurses felt that most of the health facilities provided all the basic health services required for the care of mothers and their babies. A midwife reported:

'We render antenatal services, we do delivery, we do postnatal, we have OPD too .... and then child health services; we provide that one too' (IDI, midwife).

However, the availability of some laboratory services was problematic especially in the lower level health facilities like the health centres and CHPS compounds. A few of the health centres and CHPS compounds were equipped with laboratories to conduct basic tests; like testing for malaria, syphilis, and HIV. A midwife said the following:

'We have a laboratory- we provide some lab services - not all but some' (IDI, midwife).

The lower level health facilities which do not provide laboratory services at all refer women to other facilities or private laboratories for such test services. Generally, the inadequacy of laboratory services affected the provision of comprehensive maternal health services. Some midwives and nurses indicated they resort to asking their clients to first visit the main hospital 
1 for the required laboratory testing before coming to the community level. For example, a

2 midwife said: '......so, before you even come, I will tell you that this one just go to the hospital and take your card there and do everything then you'll now continue in your community. So even if you come here, you'll be referred back to do your lab and examination there. That's why I was talking about the availability of items that we don't have' (IDI, midwife).

It was reported in the FGDs that women who visited private laboratories for tests were required to pay for them, which was a challenge. Some of the women were unable to pay for these tests. A woman said: to return home without undertaking the testing' (FGD, woman).

\section{Availability of health workforce, equipment, drugs and supplies}

Broadly, the health workforce was found to be adequate for the provision of maternal health services. The midwives and nurses considered the staffing numbers to be good, especially with the health centres and CHPS compounds. A midwife responded in relation to the question about whether the health facility had the required staff for the provision of health services: 

to years ago' (IDI, midwife).

4 It was evident that the necessary equipment, drugs and other supplies were not adequately 5 available and in good condition to aid the provision of quality health services. A nurse made 6 the following observation:

7

'The equipment I wouldn't even say we have... we have no autoclave, the forceps like this, as old as my grandmother. Even if you look at them and you are able to use them to remove a newborn baby, you will become disappointed - well rusted, visibly. As for the equipment, it's zero. And the drugs too. From now, since October 2015, we've not gotten drugs. We've not gotten drugs up till now. Apart from this paracetamol and the amoxicillin that they brought the day before yesterday. We prescribe for the women to buy' (IDI, nurse).

The midwives and nurses attributed the lack of drugs and other supplies to the delay in reimbursement by the NHIS. It was revealed that health facilities were not paid for claims submitted to the NHIS in a period of over seven months. Thus, it was difficult for health providers to procure drugs and supplies to take care of their clients. A midwife said:

'Because now we have to buy everything, and health insurance is not reimbursing us as it used to do. So, it's very difficult to get those logistics - to get money to buy the logistics. Even the medicines are also another problem' (IDI, midwife). 
1 The women confirmed the unavailability of drugs and were often given prescription forms by

2 health providers to buy drugs in pharmacies and chemical shops. A woman indicated:

3

'During my pregnancy, the nurse (midwife) told me that the drug for preventing malaria was not available and I was given a paper [prescription form] to go and buy in the shop' (FGD, woman).

Some women reported that they were unable to buy the needed drugs immediately and had to wait until they had money for the purchase. Some of the women revealed they never bought the prescribed drugs due to their unaffordability.

'To tell you the truth, my husband couldn't get money for me to buy the drugs that I was required to buy. So, I never took those drugs while pregnant' (FGD, woman).

\section{Availability of infrastructure (health facility buildings)}

Most of the CHPS compounds rendering maternal health services do not have adequate space to separately carry out the activities of antenatal, childbirth and postnatal services. These activities are carried out together in the same rooms in the health facilities. A midwife said:

'It's just the infrastructure that is the problem, because the delivery, if you have a woman in labour and the labour happens in the day time, and it's a weekday, we're definitely running ANC because our ANC is daily - we don't have particular days for ANC, no! it's daily. So, in that sense, you have to suspend one to do one. That room in there is the delivery room, the ANC room, and the lying-in room. So, in a case where you have a client who has delivered and they're still running ANC; the client is resting 
5 The lack of space meant there was no privacy provided for the women who visited the health

in that same room and they're still running the ANC in that same room. So, if you happen to get another labour, so meaning those three activities will be carried out in one small single room. So, I think the infrastructure is not that good' (IDI, midwife).

facilities. For example, a midwife reported:

'........ there's no privacy so there're certain times they'll like to do this procedure on clients, because there's somebody lying on the bed, you cannot do anything. You cannot also say Oh, madam, get up and go out with your baby and I'll attend to this one, and you cannot also tell the other woman that because of this one, go and come later' (IDI, midwife).

The available infrastructure was not properly maintained and thus not in good condition, which affected the provision of health services, including drugs. For instance, a nurse said:

'Then the storeroom for the drugs is very bad... Very bad. It's leaking, no fan, no AC [air conditioner]. So, the drugs to some extent, I can say they're not safe, they're not because of the heat inside, and you know drugs, the heat should be regulated where they keep drugs. You're supposed to regulate the heat. Put AC there to ensure that temperatures are within normal range' (IDI, nurse).

\section{Availability of transport for emergency cases}

The lack of transport for the use and provision of maternal health services was another barrier.

A suitable means of transport like ambulances, were not available at the community level to 
1 convey women with emergency conditions to higher level health facilities. If even transport

2 was available, women were not always able to afford payment for the service. A nurse said:

3

4

6

7

8

'Transportation is a big challenge for us, especially in times of emergencies. Appropriate transport is not available to carry pregnant women from their communities to this place' (IDI, nurse).

It was also difficult for lower level health facilities to refer women to higher level health facilities due to unavailability of transport. Most of the lower level health facilities did not have their own means of transport for emergency referrals. A midwife said:

'Sometimes you'll call the ambulance, the ambulance will not come. And here their means of transport is motor-king [tricycle]. How to even get the motor-king to carry a pregnant woman; and you know the motor-king is not comfortable. To carry a pregnant woman to the hospital is a problem; Taxi is a problem. So, like if we have our own means of transport it would have helped' (IDI, midwife).

Some of those health facilities that had their own vehicles (that is, pick - up vehicles and used sometimes for conveying women on referral) were not functional at the time of the study. A midwife explained:

'We have a pick-up [vehicle] but still boils down to the funds, the tyres are worn-out, so it's parked at the office. We have to buy new tyres, we don't have the money' (IDI, midwife). 
1 Given the challenges, the midwives and nurses felt that policy-makers needed to decide

2 whether they really wanted the CHPS compounds especially, to provide maternal health

3

4 services.

'If they [policy makers] don't want us to deliver babies at the CHPS level, it should be clarified so that women will just go straight to the hospital. But if we're doing it here, the work should be comfortable enough; childbirth is not something we play with - the least delay and you'll have problems' (IDI, midwife).

\section{Discussion}

This study was conducted in a rural part of Ghana, a low resource country in West Africa. The context has many similarities to other predominately rural communities where the provision of maternal health services is challenging. Our study therefore provides evidence of the demandand supply-side factors affecting the utilisation and provision of maternal health services in many low resource countries.

Both demand- and supply-side factors were perceived as barriers to the use and provision of maternal health services during pregnancy, with the exception of waiting times. For demandside, distance and time to health facilities were perceived as barriers in the survey, but not for the FGDs and IDIs. Supply-side factors such as laboratory services, equipment, drugs and other supplies were not adequately available or in good condition. Health facilities, particularly CHPS compounds also had challenges with infrastructure. Thus antenatal, childbirth and postnatal services were provided together in the same rooms. Emergency transport between communities and health facilities as well as between lower and higher-level health facilities was a challenge as well. 
1 Women in the survey perceived distance and time as barriers to the use of maternal health

2 services. The finding is in line with other studies $(18,38-40)$. In the Upper West region of

3 Ghana, a study showed that women undertake long distances in order to reach health facilities

4 (20). The finding is surprising, as CHPS compounds were experimented in the study area

5 before their scale up to other parts of the country. Therefore, the municipality has more of such

6 health facilities (18 functional CHPS compounds at the time of the study) than most districts

7 or municipalities in Ghana. Since distance to health facilities is found as a barrier in the study

8 area, the situation might be more serious in remote and recently created districts especially.

$9 \quad$ Action would be needed by policy makers to address this phenomenon.

11 Waiting times at health facilities were perceived by most women not to be a big issue. However, in Anambra state, Nigeria, women had perceived long waiting times for the use of maternal health services during pregnancy (41). Similarly, in Ghana, some studies showed prolonged waiting times for women who utilised maternal health services $(19,42)$. Probably, the existence of the CHPS compounds in the communities might have reduced congestions in the main hospital and health centres/clinics, leading to reduced waiting times for women.

In relation to supply-side factors, our study reported the unavailability of some laboratory services, equipment, drugs and other supplies in health facilities for the provision of maternal health services. Our finding is not unique. In Uganda, Wilunda et al showed that the provision of maternal health services was hindered by the lack of drugs, supplies, and basic infrastructure (40). The unavailability of some laboratory services, equipment, drugs and other supplies affect the quality of health services provided to women. Importantly, some women could not afford when required to make payments, especially for laboratory tests and drugs, which defeats the core goal of the free maternal health care policy. The cause of the unavailability of laboratory 
1 services, equipment, drugs and other supplies stem from the delay in reimbursement by the

2 NHIS. Largely, health facilities rely on funds from the NHIS for the procurement of drugs, 5 provision.

6

7 In particular, CHPS compounds had infrastructural challenges relating to the availability of supplies, and other basic essential items including reagents. There is the need for the NHIS to timely pay health facilities to allow them to purchase these basic essential inputs for service adequate space for carrying out antenatal, childbirth and postnatal services compared to health centres/clinics and the main hospital. The initial concept of the CHPS compounds in Ghana was to provide basic health services in a one or two roomed health facility, and carrying out home visits predominantly. However, with the introduction of midwifery services, these CHPS compounds were not expanded to provide adequate space for the various activities of maternal health services (antenatal, childbirth and postnatal services). Midwives had to combine different activities in one or two rooms, compromising the privacy of their clients as found in other studies $(43,44)$. Apart from the construction of more CHPS compounds, there is the need for the existing ones to be upgraded to allow them to provide comprehensive maternal health services to women. Comprehensive laboratory services should also be provided alongside. If carried out, it would allow women to have a one stop access to maternal health services in their communities and ensure their privacy as well.

Our study demonstrated the unavailability of appropriate transport for emergency referrals between communities and health facilities as well as between lower and higher-level health facilities. Other studies have found the same. For instance, transport for emergency cases was found to be a major challenge hampering the provision of maternal, neonatal and child health services in the Lao People's Democratic Republic (18). Likewise, a recent study in the Upper 
1 West region of Ghana revealed the lack of emergency transport in the CHPS compounds for

2 the referral of emergency cases (20). That study focused mainly on how transportation affected

3 the operations of the CHPS compounds. The unavailability of a suitable transport system at the

4 community level for emergencies would not allow women to receive timely treatment and this

5 has the potential to lead to loss of lives, negating the agenda of maternal deaths reduction. In

6 fact, most deaths among pregnant women occur as a result of lack of transport for referral (45,

7 46). Thus, a transportation strategy is required particularly at the community level to allow for

\section{Study limitations}

Our study has shown the factors affecting the use and provision of maternal health services from the viewpoint of women (demand) and frontline health providers (supply) under the free maternal health policy in the study area. However, recall bias cannot be ruled out, since interviews were carried out after the use of maternal health services. Thus, the interpretation of the findings should take into consideration the issue of recall bias. In addition, the study was carried out in only one district of Ghana and thus the findings have limited generalisability to the rest of the country.

\section{Conclusions}

Some demand- and supply-side factors affected the use and provision of maternal health services. Factors such as distance and time to health facilities, inadequate or unavailability of laboratory services, equipment, drugs and supplies, infrastructure as well as emergency transport affected the use and provision of maternal health services for pregnant women. The NHIS should endeavour to pay health facilities timely in order to help mitigate some of the 
1 enumerated challenges. It is also crucial to build as well as expand the infrastructure of CHPS

2 compounds. Finally, the government of Ghana and other stakeholders should prioritise the

3 provision of emergency transport for women at the community level. These together may

4 contribute to improve the use and provision of maternal health services for pregnant women,

5 leading to a reduction in maternal deaths and the achievement of universal health coverage.

6

7 List of abbreviation

8 NHIS: National Health Insurance Scheme

9 NHIA: National Health Insurance Authority

10 CHPS: Community-based Health and Planning Services

11 FGDs: Focus Group Discussions

12 IDIs: In-depth Interviews

ANC: Antenatal Care

\section{Declarations}

16 Ethics approval and consent to participate

17 The Ethical Review Board of the Navrongo Health Research Centre in Ghana and the Human Research Ethics Committee of a University in Australia gave approval for the conduct of the study; approval numbers NHRCIRB217 and ETH16-0263 respectively. Informed consent was obtained from each individual participant involved in this study.

\section{Consent for publication}

Not Applicable 
1 The datasets used and/or analysed during the current study are available from the corresponding

2 author on reasonable request.

3

\section{Competing interest}

5 The authors declare that they have no competing interests.

6

$7 \quad$ Funding

8 The University of Technology Sydney (UTS) awarded two scholarships (UTS International

9 Research Scholarship and UTS President's Scholarship) to enable the first author pursue a

10 doctoral degree in UTS. UTS WHO Collaborating Centre in Nursing, Midwifery and Health

11 also provided a travel award for data collection for the $\mathrm{PhD}$.

12

Author's contribution

PAD AYW CSEH conceived and designed the study. PAD collected the data, carried out the analysis and wrote the manuscript. Critical review was done by AYW and CSEH. Finally, all authors read and approved the manuscript.

\section{Acknowledgements}

We wish to thank the women and health providers who participated in the study. 
2

4

5

6

7

\section{References}

1. Otoo N, Awittor E, Marquez P, Saleh K. Universal Health Coverage for Inclusive and Sustainable Development: Country Summary Report for Ghana. Accra: World Bank Group, Ghana; 2014.

2. NHIA. Annual report 2009. Accra: National Health Insurance Authority, Ghana; 2010.

3. Nketiah-Amponsah E, Arthur E. Choice of Delivery Facility among Expectant Mothers in Ghana. Journal of Health Management. 2013;15(4):509-24.

4. Browne JL, Kayode GA, Arhinful D, Fidder SA, Grobbee DE, Klipstein-Grobusch K. Health insurance determines antenatal, delivery and postnatal care utilisation: evidence from the Ghana Demographic and Health Surveillance data. BMJ Open. 2016;6(3):e008175.

5. Khan SM, Singh K. The Association Between Health Insurance Coverage and Skilled Birth Attendance in Ghana: A National Study. Maternal and Child Health Journal. 2016;20(3):534-41.

6. Fenny AP, Asante FA, Arhinful DK, Kusi A, Parmar D, Williams G. Who uses outpatient healthcare services under Ghana's health protection scheme and why? BMC Health Services Research. 2016;16(1):174.

7. Bulatao RA, Ross JA. Which health services reduce maternal mortality? Evidence from ratings of maternal health services. Tropical Medicine and International Health. 2003;8(8):71021.

8. Buor D, Bream K. An analysis of the determinants of maternal mortality in sub-Saharan Africa. Journal of Women's Health (Larchmt). 2004;13(8):926-38.

9. Alvarez JL, Gil R, Hernandez V, Gil A. Factors associated with maternal mortality in Sub-Saharan Africa: an ecological study. BMC Public Health. 2009;9:462.

10. WHO U, UNFPA, World Bank Group and the United Nations Population Division. Maternal mortality: Levels and trends 2000 to 2017: estimates by WHO, UNICEF, UNFPA, World Bank Group and the United Nations Population Division Geneva: World Health Organization; 2019. Licence: CC BY-NC-SA 3.0 IGO.; 2019.

11. NHIA. NHIS Subscriber Handbook: A guide to registering and accessing NHIS. Accra: National Health Insurance Authority, Ghana; 2015.

12. NHIA. National Health Insurance Authority 2013 Annual Report. Accra: National Health Insurance Authority, Ghana; 2013.

13. Singh K, Osei-Akoto I, Otchere F, Sodzi-Tettey S, Barrington C, Huang C, et al. Ghana's National Health insurance scheme and maternal and child health: a mixed methods study. BMC Health Services Research. 2015;15(108).

14. Ensor T, Cooper S. Overcoming barriers to health service access: influencing the demand side. Health Policy Plan. 2004;19(2):69-79.

15. Jacobs B, Por Ir P, Bigdeli M, Annear PL, Damme WV. Addressing access barriers to health services: an analytical framework for selecting appropriate interventions in low-income Asian countries. Health Policy and Planning. 2011:1-13.

16. O'Donnell O. Access to health care in developing countries: breaking down demand side barriers. Cadernos de saude publica. 2007;23(12):2820-34.

17. Peters DH, Garg A, Bloom G, Walker DG, Brieger WR, Rahman MH. Poverty and access to health care in developing countries. Annals of the New York Academy of Sciences. 2008;1136:161-71.

18. Sychareun V, Phommachanh S, Soysouvanh S, Lee C, Kang M, Oh J, et al. Provider perspectives on constraints in providing maternal, neonatal and child health services in the Lao 
People's democratic republic: a qualitative study. BMC Pregnancy and Childbirth. 2013;13(1):243.

19. Baffour-Awuah A, Mwini-Nyaledzigbor PP, Richter S. Enhancing focused antenatal care in Ghana: An exploration into perceptions of practicing midwives. International Journal of Africa Nursing Sciences. 2015;2:59-64.

20. Atuoye KN, Dixon J, Rishworth A, Galaa SZ, Boamah SA, Luginaah I. Can she make it? Transportation barriers to accessing maternal and child health care services in rural Ghana. BMC Health Services Research. 2015;15(1):333.

21. Kyei-Nimakoh M, Carolan-Olah M, McCann TV. Access barriers to obstetric care at health facilities in sub-Saharan Africa-a systematic review. Systematic Reviews. 2017;6(1):110.

22. Singh A. Supply-side barriers to maternal health care utilization at health sub-centers in India. PeerJ. 2016;4:e2675.

23. Yeji F, Shibanuma A, Oduro A, Debpuur C, Kikuchi K, Owusu-Agei S, et al. Continuum of Care in a Maternal, Newborn and Child Health Program in Ghana: Low Completion Rate and Multiple Obstacle Factors. PLoS ONE. 2015;10(12):e0142849.

24. Creswell JW. Research design: qualitative, quantitative and mixed methods approaches. 4th ed. Washington DC: SAGE Publication Inc.; 2014.

25. Onwuegbuzie AJ, Leech NL. On Becoming a Pragmatic Researcher: The Importance of Combining Quantitative and Qualitative Research Methodologies. International Journal of Social Research Methodology. 2005;8(5):375-87.

26. Giddings LS, Grant BM. Mixed methods research for the novice researcher. Contemporary nurse. 2006;23(1):3-11.

27. O'Cathain A, Murphy E, Nicholl J. Why, and how, mixed methods research is undertaken in health services research in England: a mixed methods study. BMC Health Services Research. 2007;7:85.

28. GSS. Ghana Living Standards Survey Round 6 (GLSS 6) : Main Report. Accra: Ghana Statistical Services; 2014.

29. GHS. Ghana Health Service 2014 Annual Report. Accra: Ghana Health Service, Ministry of Health, Ghana; 2015.

30. WHO. Country Cooperation Strategy at a glance-Ghana. Geneva: World Health Organization; 2014.

31. MOH. Government of Ghana: National Community Health Worker (CHW) Program. Accra: Ministry of Health, Ghana; 2014.

32. Gorstein J, Sullivan KM, Parvanta I, Begin F. Indicators and Methods for CrossSectional Surveys of Vitamin and Mineral Status of Populations. The Micronutrient Initiative (Ottawa) and the Centers for Disease Control and Prevention (Atlanta). Atlanta: Centers for Disease Control and Prevention; 2007.

33. Tanahashi T. Health service coverage and its evaluation. Bulletin of the World Health Organization. 1978;56(2):295-303.

34. McIntyre D, Thiede M, Birch S. Access as a policy-relevant concept in low- and middle-income countries. Health Economics Policy and Law. 2009;4(Pt 2):179-93.

35. Levesque J-F, Harris MF, Russell G. Patient-centred access to health care: conceptualising access at the interface of health systems and populations. International Journal for Equity in Health. 2013;12(18):1-9.

36. Jat TR. Maternal health and health care in Madhya Pradesh state of India: an exploration using a human rights lens Umeå, Sweden Umeå University, SE-901 872014.

37. Saunders B, Sim J, Kingstone T, Baker S, Waterfield J, Bartlam B, et al. Saturation in qualitative research: exploring its conceptualization and operationalization. Quality \& Quantity. 2017:1-15. 
38. Stekelenburg J, Kyanamina S, Mukelabai M, Wolffers I, van Roosmalen J. Waiting too long: low use of maternal health services in Kalabo, Zambia. Tropical Medicine \& International Health. 2004;9(3):390-8.

39. Silal SP, Penn-Kekana L, Harris B, Birch S, McIntyre D. Exploring inequalities in access to and use of maternal health services in South Africa. BMC Health Services Research. 2012;12:120.

40. Wilunda C, Quaglio G, Putoto G, Lochoro P, Dall'Oglio G, Manenti F, et al. A qualitative study on barriers to utilisation of institutional delivery services in Moroto and Napak districts, Uganda: implications for programming. BMC Pregnancy and Childbirth. 2014;14(1):259.

41. Emelumadu O, Onyeonoro U, Ukegbu A, Ezeama N, Ifeadike C, Okezie O. Perception of quality of maternal healthcare services among women utilising antenatal services in selected primary health facilities in Anambra State, Southeast Nigeria. Nigerian Medical Journal. 2014;55(2):148-55.

42. Ganle JK. Why Muslim women in Northern Ghana do not use skilled maternal healthcare services at health facilities: a qualitative study. BMC International Health and Human Rights. 2015;15(1):10.

43. Ganle JK, Parker M, Fitzpatrick R, Otupiri E. A qualitative study of health system barriers to accessibility and utilization of maternal and newborn healthcare services in Ghana after user-fee abolition. BMC Pregnancy and Childbirth. 2014;14:425.

44. UNICEF. Evaluation of the free maternal health care initiative in Ghana,. Accra and Reet: UNICEF HERA/HPG 2013.

45. Jammeh A, Sundby J, Vangen S. Barriers to Emergency Obstetric Care Services in Perinatal Deaths in Rural Gambia: A Qualitative In-Depth Interview Study. ISRN Obstetrics and Gynecology. 2011;2011:10.

46. Osoro AA, Ng'ang'a Z, Mutugi M, Wanzala P. Maternal Mortality among Women Seeking Health Care Services in Kisii Level 5 Hospital. American Journal of Public Health Research. 2014;2(5):182-7. 
2 Table 1: Socio-demographic characteristics of participants

\begin{tabular}{|c|c|c|c|}
\hline \multirow{3}{*}{ Variable } & \multirow{3}{*}{ Categories } & \multicolumn{2}{|l|}{ Total } \\
\hline & & Number & $\%$ \\
\hline & & 406 & 100 \\
\hline \multirow[t]{5}{*}{ Age } & $<20$ & 41 & 10.0 \\
\hline & $20-24$ & 103 & 25.4 \\
\hline & $25-29$ & 127 & 31.3 \\
\hline & $30-39$ & 120 & 29.6 \\
\hline & $40+$ & 15 & 3.7 \\
\hline \multirow[t]{2}{*}{ Marital status } & Single & 20 & 4.9 \\
\hline & Married & 386 & 95.1 \\
\hline \multirow{4}{*}{$\begin{array}{l}\text { Highest } \\
\text { educational } \\
\text { level }\end{array}$} & No formal education & 64 & 15.8 \\
\hline & Primary/Junior High School & 226 & 55.7 \\
\hline & Senior High/Technical school & 67 & 16.5 \\
\hline & Tertiary institution & 49 & 12.0 \\
\hline \multirow[t]{6}{*}{ Occupation } & Unemployed & 29 & 7.1 \\
\hline & Trader & 79 & 19.5 \\
\hline & Farmer & 155 & 38.2 \\
\hline & Public/Civil servant & 46 & 11.3 \\
\hline & Student & 42 & 10.3 \\
\hline & Other & 55 & 13.6 \\
\hline \multirow{4}{*}{$\begin{array}{l}\text { Religious } \\
\text { background }\end{array}$} & Traditional & 20 & 4.9 \\
\hline & Catholic & 164 & 40.4 \\
\hline & Protestant & 192 & 47.3 \\
\hline & Muslim & 30 & 7.4 \\
\hline Ethnicity & Kasem & 239 & 58.9 \\
\hline
\end{tabular}




\begin{tabular}{|c|c|c|c|}
\hline & Nankam & 135 & 33.2 \\
\hline & Other & 32 & 7.9 \\
\hline Number of & 1 & 128 & 31.5 \\
\hline births & 2 & 103 & 25.4 \\
\hline & 3 & 79 & 19.5 \\
\hline & 4 or more & 96 & 23.6 \\
\hline
\end{tabular}

$7 \quad$ Table 2: Perceived distance and mode of transport to nearest health facility

\begin{tabular}{|c|c|c|c|c|c|c|c|c|c|c|c|c|}
\hline \multirow{3}{*}{$\begin{array}{l}\text { Perceived } \\
\text { distance } \\
\text { to nearest } \\
\text { health } \\
\text { facility }\end{array}$} & \multicolumn{12}{|c|}{ Mode of transport } \\
\hline & \multicolumn{2}{|c|}{ Walk } & \multicolumn{2}{|c|}{ Bicycle } & \multicolumn{2}{|c|}{ Motorbike } & \multicolumn{2}{|c|}{$\begin{array}{l}\text { Public } \\
\text { transport }\end{array}$} & \multicolumn{2}{|c|}{$\begin{array}{l}\text { Private } \\
\text { car }\end{array}$} & \multicolumn{2}{|c|}{ Total } \\
\hline & $\mathrm{N}$ & $\%$ & $\mathrm{~N}$ & $\%$ & $\mathrm{~N}$ & $\%$ & $\mathrm{~N}$ & $\%$ & $\mathrm{~N}$ & & $\mathrm{~N}$ & $\%$ \\
\hline Very near & 48 & 17.1 & 1 & 2.8 & 6 & 8.7 & 0 & 0.00 & 1 & 100 & 56 & 13.8 \\
\hline Near & 102 & 36.3 & 12 & 33.3 & 34 & 49.3 & 3 & 15.8 & 0 & 0.00 & 151 & 37.2 \\
\hline Normal & 55 & 19.6 & 13 & 36.1 & 20 & 29.0 & 5 & 26.3 & 0 & 0.00 & 93 & 22.9 \\
\hline Far & 54 & 19.2 & 9 & 25.0 & 8 & 11.6 & 6 & 31.6 & 0 & 0.00 & 77 & 19.0 \\
\hline Very far & 22 & 7.8 & 1 & 2.8 & 1 & 1.4 & 5 & 26.3 & 0 & 0.00 & 29 & 7.1 \\
\hline Total & 281 & 100 & 36 & 100 & 69 & 100 & 19 & 100 & 1 & 100 & 406 & 100 \\
\hline
\end{tabular}

